\title{
sciendo
}

\section{Glycemic index and glycemic load in preventive cardiology - the state of knowledge, selected controversies}

\begin{abstract}
The current epidemiological situation in Poland is characterized by prevalence of cardiovascular diseases (CVD) as the main cause of mortality. In the paper the current state of knowledge on the importance of glycemic index (GI) and glycemic load (GL) in CVD prevention is presented, taking into consideration the latest recommendations on CVD prevention. In a nutrition strategy based on consumption of low GI/GL foods, the target of the intervention is the profile of dietary carbohydrates which is treated as a modulator of glycemic response. In the light of the current state of research, there is no reason to treat GI/GL values as markers of pro-health qualities of the dietary plan recommended in CVD prevention to individuals with normal glucose homeostasis. However, the preventive potential of diets characterized by low GI/GL deserves a more extensive application in patients with glucose homeostasis disturbances, including those with prediabetes and insulin resistance syndrome. Taking into account the relations between abnormal carbohydrate metabolism and a risk of developing diabetes, followed by CVD, the benefits of low-glycemic diets in individuals with impaired glucose homeostasis can indirectly result in lowering the risk of CVD. It is reasonable to conduct further clinical studies on the relevance of low GI/GL diets in preventive cardiology.
\end{abstract}

Keywords: glycemic index, glycemic load, cardiovascular diseases prevention, cardiovascular diseases risk factors, clinical dietetics.

DOI: $10.2478 /$ pjph-2019-0005

\section{INTRODUCTION}

Cardiovascular diseases (CVD) are still the most frequent cause of death both in Europe and in the world. In the European countries over 4 million people die every year due to this problem [1]. In Poland in 2016, CVDs accounted for about $43.3 \%$ of all fatalities and they remained a major cause of premature male mortality. As a result, the length of life of Polish males is shorter by 4.6 years than the average lifespan in the EU countries and corresponds to the life expectancy in all EU countries in 1999, that is 16 years ago [2]. It is estimated that the number of fatalities caused by CVD will exceed 200.000 in 2020 at the current pace of aging of the Polish population [3]. The high CVD risk is a reflection of the global epidemiological situation characterized by preponderance of non-communicable diseases (NCD) as the leading cause of mortality. The global WHO data show that in 2015, 39.5 million people died of NCD, which accounts for $70 \%$ of 56 million deaths worldwide. In 2015 about $48 \%$ of fatalities caused by NCD in low- and middle-income countries referred to individuals before the age of 70, therefore they could have been considered premature deaths. The most common causes of global mortality indicated by the WHO include: heart diseases, stroke, cancer, and diabetes (DM). The WHO emphasizes that $80 \%$ of premature deaths caused by NCD could have been avoided by the effective modification of behavioral risk factors [4].
Prevention is defined as a set of closely interrelated measures aimed at the reduction of morbidity or alleviation of symptoms and reduction of complications of existing illnesses [5]. In recent years several scientific societies have updated their recommendations for CVD prevention [5-7]. Consequently, the aim of this study is the analysis and presentation of current guidelines concerning nutritional aspects of CVD prevention, taking into special account the diets in which the values of glycemic index (GI) and glycemic load (GL) are manipulated.

\section{Evidence-based diets applicable in CVD prevention}

According to the guidelines of the European Atherosclerosis Society (EAS) and the European Society of Cardiology (ESC), the strongest potential to prevent and treat CVDs, verified by RCT, has a nutrition strategy based on the Mediterranean diet or the related DASH diet (Dietary Approaches to Stop Hypertension), particularly with respect to blood pressure (BP) control [5]. In this context the Polish Society of Die-tetics [7] suggests the DASH diet in the first place, defining this nutrition strategy as "the world's healthiest diet", then the Mediterranean and Portfolio diets. Both DASH and the Mediterranean diets are characterized by a high consumption of fruit, vegetables and whole-grain products, legumes, nuts, fish, poultry, and low-fat dairy products, as well as by a reduced consumption of sweets, sugar-sweetened beverages, red meat, whereas olive oil is used as a source of monounsaturated 
fatty acids (MUFA) [5]. The Polish Society of Dietetics also regards diets based on low-GI products as potentially preventive in cardiac patients with overweight and obesity, atherogenic dyslipidemia and insulin resistance [7]. This attitude is consistent with the guidelines provided by the International Carbohydrate Quality Consortium (ICQC), which considers the quality of high-carbohydrate meals expressed by low GI/GL indexes to be essential in prevention in patients who are sedentary, overweight and at an increased risk of diabetes mellitus type 2 (T2DM) [8]. However, the ICQC notes that both parameters should be examined in terms of pro-health qualities of overall dietary patterns, in addition to the presence of ingredients considered as healthy, such as fiber or wholegrain products. The ICQC emphasizes that diets characterized by low GI/GL are particularly advisable for individuals with insulin resistance because of their beneficial influence on postprandial glycemia (PPG) [8]. This means that the recommendations for this nutrition model refer specifically to the group of cardiac patients who are subject to numerous CVD risk factors related to disturbed glucose homeostasis. Therefore, this model is not applicable to primary prevention in healthy individuals.

Nevertheless, the latest guidelines for CVD prevention set out by the European Society of Cardiology (ESC) [6] consider the Mediterranean diet the only nutrition model with a potential to decrease the CVD incidence or mortality. It was found that following this diet over a period of five years, in comparison with a control diet, lowered the risk of developing CVD by $29 \%$. The ESC experts stress that in the case of patients with $\mathrm{DM}$, the eating plan which minimizes hyperglycemia can reduce the risk of vascular complications and CVD, yet they do not indicate a low GI/GL diet as a preferred strategy to achieve such targets [6]. The attitude of the ESC is thus much more cautious than that of the ICQC.

According to the latest recommendations given by the Polish Diabetes Association in 2019, GI can be implemented in the dietary treatment of DM and is useful in supporting the normalization of glycemia, which indirectly brings benefits in CVD prevention. The guidelines indicate that whole-grain products, especially those with low GI (>55 GI) should be the main source of carbohydrates for DM patients. Observing the principle of low GI values also helps to increase the percentage of energy derived from carbohydrates present in the diet, if necessary, from the recommended $45 \%$ to $60 \%$, for example in the case of diabetic patients involved in intense physical activity [9].

\section{GI and GL as indicators of glycemic reaction to carbohy- drate consumption}

The carbohydrate profile present in a diet is the focus of intervention in the nutrition strategy based on low GI/GL foods. This approach is a reaction to contemporary diets characterized by the low fiber content and which are energy dense, digested and absorbed fast, producing sharp increases in glycemia and postprandial insulinemia [8]. Preferential consumption of complex carbohydrates helps to modify the glycemic response (GR) after their consumption in such a way that PPG, which is a proven CVD risk factor, decreases.

GI was suggested in 1981 as a criterion for the classification of food containing carbohydrates, to be used by DM patients in their dietary choices [10-12]. The concept of GI is based on an assumption that the presence of diversified carbohydrates in food results in different GR changes and different metabolic effects [12]. The ICQC defines GI as:

"the GR elicited by a portion of food containing $50 \mathrm{~g}$ (or in some cases $25 \mathrm{~g}$ ) of available carbohydrate and is expressed as a percentage of the GR elicited by $50 \mathrm{~g}$ ( $\mathrm{or} 25 \mathrm{~g}$ ) of the reference carbohydrate (i.e. either a glucose solution or white bread, defined respectively as the glucose scale or the bread scale)" $[8]$.

The GI index is a predictor of the pace at which carbohydrates induce GR [13]. It should be noted that different carbohydrates can cause GR that may differ even 4-5 times [8]. Consequently, carbohydrates are classified not only with reference to their structure (simple or complex), but also because of the GR they stimulate. The most beneficial for the health are those in which GI does not exceed 50. They include the products that are a good source of fiber, such as low-starch vegetables, whole-grain products and fruit.

The following formula is used to calculate GI:

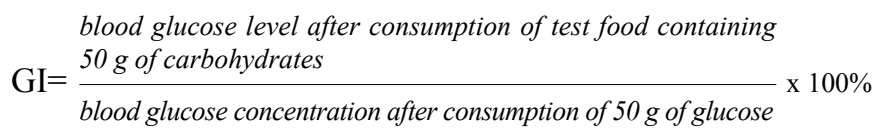

However, the GI value of foods depends not only on the kind of carbohydrates, but also on a number of different factors. They include, inter alia, the physical form of a product, starch form and content, including the proportion of amylose to amylopectin (the higher the ratio, the lower GI of a product; wheat flour has a high GI because of the high content of highly branched amylopectin, which is digested faster) [14]; in addition, the macroelement content of a product, the presence of proteins and fats, as well as organic acids (lactic acid, propionic acid, acetic acid), pectins, tannins and phytic acid (which inhibit starch digestion). GI values depend also on the fiber content of a product; however, it refers only to the soluble fraction of fibrin (it delays stomach emptying and slows the activity of digestive enzymes) [15]. In addition, GI values depend on the degree of processing and disintegration of a product, which determines its accessibility to digestive enzymes (e.g. the size of starch pellets depends on grinding, crushing, etc.: the smaller the pellet, the higher its accessibility to digestive enzymes, and the higher GI value), ripeness of fruit, product temperature (higher temperature is related to higher PPG), moreover, the time of a day, the rate at which a meal is consumed, also the features of a meal consumed earlier (the so-called next meal effect, which consists in the fact that the high GI meal consumed earlier increases the GI of the following meal) $[14,15]$. The GI assessment of complex meals and predicting certain GR on their basis should therefore include the complex impact of other nutrients present in the meal [8]. The impact of different factors on GI is shown in Table 1.

GI does not take account of carbohydrate content in a portion of food. Products with a high GI can contain minor amounts of absorbable carbohydrates in a standard consumed portion [17]. GL was intended to allow prediction of the actual food impact on PPG, without the indicated limitations. GL is based on two variables: GI level and the size of a standard portion. GL applicability in dietetics stems from the assumption that high GI products consumed in smaller portions generate 
a postprandial insulin burst at a comparable rate as do products with lower GI, eaten in bigger portions. The ICQC defines GL as follows:

"the product of GI and the total available carbohydrate content in a given amount of food (GL $=$ GI $x$ available carbohydrate/given amount of food)" [8].

In 2002, standardized tables presenting GI and GL were published by The American Journal of Clinical Nutrition, in which over 1300 products were included. The final version of the updated tables was made available in 2008 by Diabetic Care [18]. The examples of GI and GL levels in selected food products are shown in Table 2.

TABLE 1. Factors influencing GI of foods (based on [16]).

\begin{tabular}{lc}
\hline \multicolumn{1}{c}{ Factor tested } & Impact on GI levels \\
\hline $\begin{array}{l}\text { Type and proportions } \\
\text { of monosaccharides }\end{array}$ & $\begin{array}{c}\text { Higher GI concentration } \uparrow \\
\text { Higher galactose concentration } \uparrow \\
\text { Higher fructose concentration } \downarrow\end{array}$ \\
\hline $\begin{array}{l}\text { Starch content } \\
\text { and characteristics }\end{array}$ & $\begin{array}{c}\text { Higher amylopectin concentration } \uparrow \\
\text { Higher amylose concentration } \downarrow\end{array}$ \\
\hline Product composition & Resistant starch $\downarrow$ \\
\hline Higher fat content than carbohydrate content $\downarrow$ \\
Higher protein content $\downarrow$ \\
Higher content of organic acids (lactic acid, propi- \\
onic acid, acetic acid) $\downarrow$
\end{tabular}

TABLE 2. GI and GL levels in portions of selected products (based on [18]).

\begin{tabular}{|c|c|c|c|}
\hline Product & $\begin{array}{c}\text { Portion } \\
\text { (in grams) }\end{array}$ & GI & GL \\
\hline \multicolumn{4}{|c|}{ Low glycemic index (GI 0-55) } \\
\hline Buckwheat & 150 & 54 & 16 \\
\hline Pumpernickel bread & 30 & 50 & 6 \\
\hline Orange & 120 & 42 & 5 \\
\hline Apple & 120 & 38 & 6 \\
\hline Lentils & 150 & 29 & 5 \\
\hline \multicolumn{4}{|c|}{ Medium glycemic index (GI 56-69) } \\
\hline Dark grapes & 120 & 59 & 11 \\
\hline Cooked spaghetti & 180 & 61 & 27 \\
\hline Dried figs & 60 & 61 & 16 \\
\hline Raisins & 60 & 64 & 28 \\
\hline Red beets & 80 & 64 & 5 \\
\hline \multicolumn{4}{|c|}{ High glycemic index $(G I \geq 70)$} \\
\hline Plain baguette & 30 & 95 & 15 \\
\hline Cornflakes & 50 & 81 & 21 \\
\hline Broad beans & 80 & 79 & 9 \\
\hline French fries & 150 & 75 & 22 \\
\hline Watermelon & 120 & 72 & 4 \\
\hline
\end{tabular}

GL levels for standard portions of consumed products are classified as: low (GL $\leq 10)$, medium (GL $11-19)$, and high $(\mathrm{GL} \geq 20)$. In dietary practice, the GL of a daily allowance of food not exceeding 80 is regarded as low while GL higher than 120 is interpreted as high [7].

\section{The importance of GI and GL in CVD prevention - the} current state of knowledge

The latest review of the state of research in $2006-2018$ on the role of GI and GL in CVD prevention by Vega-López S. et al. recommends a cautious approach to GI/GL as markers of the value of diets in CVD prevention [12]. Firstly, crosssectional data is inconsistent in terms of the direction and strength of relationship between GI/GL and body weight. As a result there are no grounds for claiming that the two indexes play a significant role in maintaining body weight. As foods with low GI are characterized by high fiber content, it is suggested that any associations of GI with body weight may be influenced by dietary fiber. Thus, there are no grounds to prescribe low GI-based diets in obesity as an alternative to a weight-loss plan in the treatment of obesity [12]. Secondly, there are no consistent results of cross-sectional studies evaluating the influence of GI/GL on glucose homeostasis indexes and insulin resistance. It is suggested that the possible benefits shown in some studies may be attributable to a higher fiber or reduced carbohydrate content. The aforementioned review emphasized that the prospective studies on the association between GI/GL levels and T2DM risk demonstrated a stronger predictive value of GL [12]. Thirdly, with regard to $\mathrm{GI} / \mathrm{GL}$ association with CAD risk factors, the analysis carried out by Vega-López $\mathrm{S}$ et al. indicated that there is no consistent evidence for the impact of low GI/GL diets on the lipid profile, and the range of evidence for influence on other CAD risk factors is limited. Furthermore, prospective observations do not provide any strong evidence for the impact of low GI/GL diets on CVD incidence or mortality [12]. Similar findings are shown in meta-analysis by Clar et al. [19] published in Cochrane Database of Systematic Reviews, which encompassed 21 RCTs with the total number of 2538 participants, aimed to assess the effect of low GI diets or foods compared to higher GI diets or foods on CVD risk factors. In the primary prevention studies no differences in the lipid profile or RR were reported in comparison groups, and similarly, in one analyzed study on secondary prevention. According to the authors of the meta-analysis, there are no reasons to claim that low GI diets find application in CVD prevention [19]. Also, according to the meta-analysis by Kristo et al., the existing evidence for the influence of a dietary glycemic load on CVD risk does not allow drawing explicit conclusions as no consistent effects of the dietary GI/GL values on CVD risk factors have been demonstrated yet [20].

The meta-analyses in question should be treated as a prerequisite for the correction of the earlier ICQC standpoint of 2015, which claimed that "there is convincing evidence from a large body of prospective cohort studies that low GI/GL diets reduce the risk of CAD", which could result from their beneficial impact on the lipid profile and markers of inflammation [8]. The lack of a significant effect of the glycemic value of diet on the level of CAD risk can result from the fact that these parameters do not significantly affect LDL-C, which is the primary predictor of atherosclerosis development [5,6]. It is stressed that carbohydrates, especially the refined ones, when 
used as a substitute for saturated fatty acids (SFA) may pose a risk of an increase of TG and decrease of HDL-C. The minimization of this adverse effect is possible by selecting low GI carbohydrates of slow digestion and absorption. The effect is particularly important in patients with metabolic syndrome or DM [5]. Thus, from the perspective of CVD prevention, only low GI carbohydrates, apart from mono- and polyunsaturated fatty acids, can probably be a valuable alternative to SFA as a source of energy [8]. The mentioned effect of slowed digestion and carbohydrate absorption is used in treatment with alpha-glucosidase inhibitors (acarbose) [21].

In the context of this part of the analysis, it is worth referring to the meta-analysis by Clifton PM et al. of 2019, comprising 84 studies, which demonstrated that replacing high GI products with low GI products substantially decreased triglyceride (TG) concentration (by 15-20\%) [22]. Worth noting is also the research by Castro-Quezada et al., who studied the relationship between the GI/GL of diet and CVD risk in individuals at the age of 60-74 ( $\mathrm{n}=343)$. Total cholesterol levels, LDL-C, TG, and apoliprotein A1 (apo-AI, apo-AII) were examined in the study. It was only demonstrated that dietary habits and TG reduction were related (every $10 \mathrm{GL}$ units increased TG by 0.70 $\mathrm{mg} / \mathrm{dl}$ ) [23]. Taking into account the importance of LDL-C as a primary target in $\mathrm{CAD}$ prevention [6], there is no reason to expect that the correction of the lipid profile obtained through GI/GL modification will bring an effective reduction of CAD risk. The lack of a significant effect of manipulating GI/GL indexes on CVD risk was also demonstrated in a controlled feeding study OmniCarb involving 163 overweight adult participants of 2017. It was found that administering low GI carbohydrates as part of the general DASH nutrition plan did not bring any significant benefits as far as CVD risk factors were concerned [24]. Interesting results concerning the impact of GI/GL on BP were obtained from the meta-analysis by Evans et al. [25], in which 14 trials comprising 1097 participants, conducted over the period of at least 6 weeks, were analyzed. Their subsequent analysis revealed that lower-glycemic diets are associated with significantly better and more advantageous BP profiles. However, no clear dose response was established. The weakness of the findings is, however, that the studies were largely aimed to reduce body mass and the BP measurements were not their primary outcome; furthermore, they involved too small groups of studied patients, which prevented the detection of slight BP changes. The authors claim that high-quality trials in healthy normal-weight populations are necessary in order to establish the influence of GI/GL diets on BP before any possible suggestions for including this type of diets in the nutrition policy are offered [25].

On the other hand, the potential of low-glycemic diets seems to deserve wider implementation in preventing DM. Indirectly, considering the connection between carbohydrate metabolism disorders and CVD risk, the benefits in this area would also translate into a lowered CVD risk. In 2017 Cheng et al. published the results of their research in which the relationship between high GI/GL products and disrupted glucose homeostasis was assessed in 3918 Chinese adults without diagnosed DM. The GI and GL parameters had considerable importance for glucose homeostasis while their anti-health values were related to higher odds of prediabetes, especially in individuals with higher genetic T2DM risk [26]. A conclusion cannot therefore be excluded that the benefits of reducing the CVD risk from using low-glycemic diets can be expected only in certain co- horts with high T2DM risk related to abnormal glucose homeostasis. It is worth noting that a ten-year prospective observation of a cohort comprising 75.521 American women revealed a relationship between GL values and CAD risk, however, it was most evident among women with body weights above average [17]. In contrast, the results obtained by Shikana et al. show that diets of different GI/GL values did not cause substantial differences in the levels of CAD risk factors in the group of individuals with obesity [27]. It is a known fact that prediabetic individuals are in danger of developing T2DM and its microand macroangiopathic complications [28,29] related, among others, to the process of nonenzymatic glycation of proteins and formation of advanced glycosylation end-products (AGE). Furthermore, the process of glyoxylation-glycation of LDL intensifies the atherogenic effect of this cholesterol fraction [30]. Glycated LDL lipoproteins also modify the functions of blood platelets [31]. In addition, high PPG increases oxidative stress, resulting in endothelial damage of blood vessels [32]. The relationship between DM and higher CVD risk is confirmed by the results of an eighteen-year prospective study by Jutilainen et al. $(n=905)$ whose goal was to examine the impact of T1DM and T2DM on CVD-related mortality. The conclusions proved that the mortality rate per 1000 individuals was 23.1 for T1DM and 35.3 for T2DM respectively; whereas the mortality rate of 4.6 was noted among persons not suffering from DM [33].

\section{CONCLUSIONS}

Considering the multifaceted determinants of GI/GL values of diets, which result both from the dietary content, including the proportions of macro-components, and the presence of other diet constituents described earlier in the paper, it is reasonable to focus, as part of nutritional health policy, not only on single nutrients but also to overall dietary patterns. Before the 1980s, clinical dietetics was dominated by an approach geared towards correcting dietary deficits. However, the latest findings indicate that metabolic health depends mainly on overall dietary patterns, what results from synergistic interactions between individual dietary components [34]. This approach also concerns the impact of diets on CVD risk. The so-called "western feeding patterns" are known to generate insulin resistance and chronic inflammation, and to be conducive to T2DM and CVD incidence. It still remains a challenge to find healthy eating patterns that would be acceptable to people, consistent with their individual preferences and feasible in everyday nutrition.

\section{SUMMARY}

- Dietary management lies in the centre of primary and secondary CVD prevention. Diet plans with low SFA and TFA content play a fundamental role in dietary CVD prevention as they have a potential of lowering LDL-C.

- There is no consistent evidence of significant influence of low GI/GL diets on CVD risk levels and CVD incidence or mortality.

- A dietary strategy based on low GI/GL values can be beneficial to patients with impaired glucose homeostasis and at high risk of T2DM development.

- From the perspective of preventive cardiology, it is necessary to conduct rigorously designed intervention studies 
testing the impact of different carbohydrate quality diets on metabolic health and clinical endpoints.

- Nutrition education should convey a message that prohealth qualities of a properly balanced comprehensive diet are essential in CVD prevention.

- The quality and content of carbohydrates in a nutrition strategy should be considered in the context of overall healthy dietary patterns.

\section{REFERENCES}

1. Nichols M, Townsend N, Scarborough P, et al. Cardiovascular disease in Europe 2014: epidemiological update. Eur Heart J. 2014;35:2950-9.

2. Wojtyniak B, Goryński P. Sytuacja zdrowotna ludności Polski i jej uwarunkowania - synteza. Warszawa: Narodowy Instytut Zdrowia Publicznego - Państwowy Zakład Higieny; 2018.

3. Strzelecki Z, Szymborski J. Zachorowalność i umieralność na choroby układu krążenia a sytuacja demograficzna Polski. Warszawa: Rządowa Rada Ludnościowa; 2015.

4. Global Health Observatory (GHO). http://www.who.int/gho/ncd/en/ (accessed on 19 May 2017).

5. Captano AL, Graham I, De Backer G, et al. Wytyczne ECS/EAS dotyczące leczenia zaburzeń lipidowych. Kardiol Pol. 2016;74(11):1234-318.

6. Piepoli MF, Hoes AW, Agewall S, et al. 2016 European Guidelines on cardiovascular disease prevention in clinical practice: The sixth joint task force of the European society of Cardiology and other societies on cardiovascular disease prevention in Clinical Practice. Eur J Prev Cardiol. 2016;37:2315-81.

7. Polskie Towarzystwo Dietetyki. Standardy postępowania dietetycznego w kardiologii, stanowisko Polskiego Towarzystwa Dietetyki 2016. Dietetyka. 2016;9 (special ed.):1-36.

8. Augustin LS, Kendall CW, Jenkins DJ, et al. Glycemic index, glycemic load and glycemic response: An International Scientific Consensus Summit from the International Carbohydrate Quality Consortium (ICQC). Nutr Metab Cardiovasc. 2015;25(9):795-815.

9. Gumprecht J. Guidelines on the management of diabetic patients. A position of Diabetes Poland 2019. Clin Diabetol. 2019;8 (1):1-94.

10. Jenkins DJ, Wolever TM, Taylor RH, et.al. Glycemic index of foods: a physiological basis for carbohydrate exchange. Am J Clin Nutr. 1981;34:362-6.

11. Ludwig DS. The glycemic index: physiological mechanisms relating to obesity, diabetes, and cardiovascular disease. JAMA. 2002;287(18):241423.

12. Vega-López S, Venn BJ, Slavin JL. Relevance of the glycemic index and glycemic load for body weight, diabetes, and cardiovascular disease. Nutrients. 2018;10:1-27.

13. Wolever TM, Jenkins DJ, Jenkins AL, et al. The glycemic index: methodology and clinical implications. Am J Clin Nutr. 1991;54:846-654.

14. Ostrowska J, Jeznach-Steinhagen A. Czynniki wpływające na wartość indeksu glikemicznego oraz jego zastosowanie w leczeniu dietetycznym cukrzycy. Forum Med Rodz. 2016;10(2):84-90.

15. Adamska E, Górska M. Indeks i ładunek glikemiczny diety. Prz Kardiodiabetol. 2008;3 (3):223-31.

16. Kulczyński B, Gramza-Michałowska A. Znaczenie indeksu i ładunku glikemicznego w zapobieganiu rozwoju chorób sercowo-naczyniowych. Probl Hig Epidemiol. 2015;96 (1):51-6.

17. Liu S, Willett WC, Stampfer MJ, et al. A prospective study of dietary glycemic load, carbohydrate intake, and risk of coronary heart disease in US women. Am J Clin Nutr Jun. 2000;71:1455-61.

18. Atkinson FS, Foster-Powell K, Brand-Mille J. International tables of Glycemic Index and Glycemic Load Values. Diabetes Care. 2008;31(12):2281-3.

19. Clar C, Al-Khudairy L, Loveman E, at.el. Low glycemic index diets for the prevention of cardiovascular disease. Cochrane Database Syst Rev. 2017;31(7):2-130.

20. Kristo AS, Matthan NR, Lichtenstein AH. Effect of diets differing in glycemic index and glycemic load on cardiovascular risk factors: Review of randomized controlled-feeding trials. Nutrients. 2013;5:1071-80.

21. Mathews MJ, Liebenberg L, Mathews EH. How do high glycemic load diets influence coronary heart disease? Nutr Metab. 2015;12(6):1-15.

22. Clifton PM. Diet, exercise and weight loss and dyslipidaemia. Pathology. 2019;51(2):222-6.

23. Castro-Quezada I, Artacho R, Molina-Montes E, et al. Dietary glycemic index and glycemic load in a rural elderly population (60-74 years of age) and their relationship with cardiovascular risk factors. Eur J Nutr. 2015;54(4):523-34.

24. Sacks FM, Carey VJ, Anderson CA, at el. Effects of high vs low glycemic index of dietary carbohydrate on cardiovascular disease risk factors and insulin sensitivity. The OmniCarb Randomized Clinical Trial. JAMA. 2014;312(23):2531-41.

25. Evans CE, Greenwood DC, Threapleton DE, et al. Glycemic index, glycemic load, and blood pressure: a systematic review and meta - analysis of randomized controlled trials. Am J Clin Nutr. 2017;105:1176-90.

26. Cheng G, Xue H, Luo J, et al. Relevance of the dietary glycemic index, glycemic load and genetic predisposition for the glucose homeostasis of Chinese adults without diabetes. Sci Rep. 2017;7:400.

27. Shikany JM, Phadke RP, Redden DT, et al. Effects of low high - glycemic indeks/glycemic load diets on coronary heart disease risk factors in overweight/obese men. Metabolism. 2009;58(12):1793-801.

28. Skrzypek M, Krzyszycha R, Szczygieł K, et al. Zapobieganie konwersji stanu przedcukrzycowego do cukrzycy typu 2 jako wyzwanie współczesnego zdrowia publicznego. Analiza aktualnego stanu badań, możliwości interwencji. Medycyna Ogólna i Nauki o Zdrowiu. 2018;24(4):214-9.

29. Skrzypek M, Krzyszycha R, Szczygieł K, et al. Możliwości zapobiegania konwersji stanu przedcukrzycowego do cukrzycy typu 2 z perspektywy dietetyki klinicznej. Strategie interwencyjne dotyczące stylu życia. Medycyna Ogólna i Nauki o Zdrowiu. 2018;24(4):220-7.

30. Szutowicz A. Hiperglikacja białek wewnątrz i zewnątrzkomórkowych; marker czy aktywny element patomechanizmów cukrzycy. Diagn Lab. 2015;51(3):213-20.

31. Ferretti G, Rabini RA, Bacchetti TA, et al. Glycated low density lipoproteins modify platelet properties: A compositional and functional study. J Clin Endocrinol Metab. 2002;87(5):2180-4.

32. Pischon T, Girman CJ, Hotamisligil GS, et al. Plasma adiponectin levels and risk of myocardial infarction in men. JAMA. 2004;291(14):1730-7.

33. Jutilainen A, Lehto S, Rönnemaa T, et al. Similarity of the impact of type 1 and type 2 diabetes on cardiovascular mortality in middle - aged subjects. Diabetes Care. 2008;31(4):714-9.

34. Archundia Herrera MC, Subhan, FB, Chan CB. Dietary patterns and cardiovascular disease risk in people with type 2 diabetes. Curr Obes Rep. 2017;6(4):405 13 .

\section{Corresponding author}

Dr hab. Michał Skrzypek

Department of Clinical Dietetics, Medical University of Lublin,

Chodźki 1 St., 20-093 Lublin

E-mail: michal.skrzypek@umlub.pl

tel. +48814486900 